\title{
DESIGN OF MESOPOROUS CARBON FIBERS FROM A POLY(ACRYLONITRILE) BASED BLOCK COPOLYMER BY A SIMPLE TEMPLATING COMPRESSION MOULDING PROCESS
}

\author{
Jean-Michel Thomassin, ${ }^{a}$ Antoine Debuigne,${ }^{a}$ Christine Jérôme ${ }^{a}$ and Christophe Detrembleur ${ }^{\star a}$ \\ ${ }^{a}$ Center for Education and Research on Macromolecules (CERM), University of Liège, Sart-Tilman, B6, 4000 \\ Liège, Belgium. Fax: 32-4-3663497; Tel: 32-4-3663465; E-mail: christophe.detrembleur@ulg.ac.be
}

\begin{abstract}
In this poster, we report a templating compression moulding process for preparing mesoporous carbon fibers using a poly(vinyl acetate)- $b$-poly(acrylonitrile) (PVAc-b-PAN) block copolymer, the PVAc block being the sacrificial block while PAN is the carbon precursor. In this process, an anodic aluminum oxide (AAO) membrane is used as the template for the penetration of the block copolymer. This technique has been widely used for classical block copolymers (Poly(styrene)-b-poly(butadiene) ${ }^{1,2}$, Poly(styrene)- $b$-poly(methyl methacrylate) ${ }^{3}$, Poly(styrene)- $b$-poly(ethylene oxide) ${ }^{4}$, Poly(styrene)- $b$ poly(2-vinylpyridine $)^{5}$ ) by simply depositing the AAO template on the top of a molten copolymer film. The strong capillary forces drew the copolymer inside the nanopores of the template. However, our carbon precursor block (poly(acrylonitrile)) of the copolymer is infusible which prevents the use of this method. We therefore develop a compression moulding process to force the copolymer to enter the template. The second block has a dual role of (i) favoring the penetration of the block copolymer inside the nanopores of the template, thanks to its low $\mathrm{Tg}$, and (ii) creating the nanopores in the final carbon fibers by pyrolysis and volatilization at high temperature. The influence of the PAN/PVAc ratio and the heating rate during pyrolysis on the porous morphology of the fibers was studied by transmission electron microscopy (TEM).
\end{abstract}

\section{References}

1. H. Xiang, K. Shin, T. Kim, S. I. Moon, T. J. McCarthy and T. P. Russell, Macromolecules, 2004, 37, 5660-5664. 2. H. Xiang, K. Shin, T. Kim, S. I. Moon, T. J. McCarthy and T. P. Russell, Macromolecules, 2005, 38, 1055-1056.

3. Y. Wang, U. Goesele and M. Steinhart, Chem. Mater., 2008, 20, 379-381.

4. J.-T. Chen, M. Zhang, L. Yang, M. Collins, J. Parks, A. Avallone and T. P. Russell, J. Polym. Sci., Part B: Polym. Phys., 2007, 45, $2912-2917$.

5. Y. Wang, Y. Qin, M. Knez, U. Goesele and M. Steinhart, PMSE Prepr., 2009, 100, 629-630. 